\title{
KONTRIBUSI TOKOH PUNAKAWAN PADA PAGELARAN WAYANG KULIT TERHADAP PENDIDIKAN ISLAM KEPADA MASYARAKAT
}

\author{
Eddy Saputra \\ Program Studi Teknik Informatika, Universitas Indraprasta PGRI \\ Email: saputra2578@gmail.com
}

\begin{abstract}
Abstrak
Wayang sebagai satu-satunya hiburan masyarakat dijadikan media pendekatan untuk menyampaikan ajaran Islam, inilah yang diadopsi oleh Sunan Kalijaga sebagai media dakwah. Dengan memasukan tokoh baru yaitu Punakawan di tengah tokoh yang sudah popular yaitu pandawa lima, padahal punakawan ini tidak ada pada cerita aslinya. Wayang begitu melekat dengan budaya dan tradisi Jawa, ceritanya diambil dari negeri India. Tokoh Punakawan menjadi pembeda dalam cerita wayang kulit di Jawa dengan nama khas jawa Punakawan memiliki makna yang syarat dengan nilai-nilai ke Islaman. Punakawan juga mengajarkan moderasi dalam beragama yang tidak bersinggungan dengan budaya lokal. Penelitian ini menggunakan pendekatan studi pustaka, data yang dikumpulkan melalui buku, catatan, kisah-kisah sejarah dan yang lainnya. Tujuan penulisan ini bahwa dakwah dapat menggunakan media yang tidak bersinggungan dengan budaya yang sudah ada. Pendidikan Islam selalu mengedepankan pendekatan akhlak dan moral, dari aspek inilah tokoh Punakawan dimunculkan. Masyarakat Jawa begitu meyakini keberadaan tokoh Punakawan seakan-akan pernah hidup di dunia nyata, sebagai contohnya Gunung Tidar yang ada di Kabupaten Cilalap diyakini sebagai tempat diamana Semar tinggal.
\end{abstract}

Kata Kunci : Punakawan, Wayang Kulit, Pendidikan Islam

\begin{abstract}
Wayang as the only entertainment for the people is used as a media approach to convey Islamic teaching values. This is adopted by Sunan Kalijaga as a media approach. By including a new character which is The Punakawan in the middle of a popular character previously, Pandawa Lima, even though it is not in the original story. Wayang is so attached to Javanese culture and tradition although that story is taken from India. The punakawan figure becomes a differentiator in the wayang kulit story that is carried out with the Javanese punakawan's distinctive name having a prerequisite meaning with Islamic values. Punakawan also teaches moderation in religion that does not intersect with local culture. This study uses a literature study approach, data collected through books, notes, historical stories and others. Islamic education always puts forward a moral and moral approach, from this aspect, the Punakawan figures are raised. The Javanese people believe that the existence of Punakawan figures seems to have lived in the real world, for example Mount Tidar in Cilalap Regency is believed to be the place where Semar lives.
\end{abstract}

Key Words : Punakawan, Wayang Kulit, Islamic Education

\section{PENDAHULUAN}

Penelitian terdahulu hanya menyampaikan peran penting dari Wali Songo sebagai penyebar Islam di Jawa, keterangan ini terdapat dalam artikel dengan judul Nilai Filosofi Wayang Kulit sebagai Media Dakwah [1].

Dakwah yang disampaikan kebanyakan hanya mengedepankan peran Wali Songo sebagai dalang, sementara dalam pementasan wayang ada tokoh sentral yang begitu lekat yakni Punakawan, tokoh lokal yang sangat sentral perannya dalam membantu para Pandawa (lima tokoh yang digambarkan sebagai kebaikan) dalam memerangi musuh-musuhnya yaitu Kurawa (lebih dari seratuh tokoh jahat yang memerangi Pandawa).

Penelitian ini lebih kepada Tokoh lokal Punakawan dalam pagelaran wayang kulit, 
dimana kontribusi Punawakan sangat besar dalam menyampaikan Pendidikan Islam kepada masyarakat. Nama tokohnya sangat dekat dan lekat dengan masyarakat Jawa, bahkan Punakawan menjadi tokoh utama dari pada tokoh utama aslinya.

Wayang kulit merupakan kesenian yang dapat menjadi identitas bangsa Indonesia, sekalipun ceritanya sering disampaikan dalam setiap pagelarannya diadopsi dari kisah-kisah yang ada di India, tidak jarang di dalamnya dimasukan pesan-pesan kekinian. Ini masih sering dilakukan oleh para dalang dalam meyampaikan pendapat atau aspirasi. Kemunculan wayang kulit pada abad ke empat belas membawa perubahan besar bagi masyarakat Jawa khususnya dan masyarakat Indonesia pada umumnya.

Wayang kulit berkontribusi membawa peradaban bagi masyarakat Jawa. Kehidupan masyarakat lebih teratur dan terarah, nilai-nilai kebersamaan serta gotong royong mulai tumbuh, semangat persaudaraan terbangun, hidup rukun saling menghargai satu dengan lainnya semua berdampingan dalam wadah persatuan.

Persatuan yang dibangun di atas landasan nilai-nilai keislaman yang rutin disampaikan Sunan Kalijaga dalam setiap pementasan wayang kulit yang sering dilakukan di tengah-tengah masyarakat menjadi satu-satunya hiburan kala itu. Wayang kulit digunakan sebagai media menyampaikan pendidikan Islam oleh Sunan Kalijaga dalam menyebarkan agama Islam di tanah Jawa.

Cerita dan tokoh yang disampaikan tidak asing untuk masyarakat, kisah Mahabrata dan Ramayana begitu akrab di telinga dan itu sangat wajar, karena sebelum Islam datang di Jawa, masyarakat Jawa sudah menganut agama Hindu dan Budha yang tidak bisa dipisahkan dari tokoh dan cerita tersebut, di mana cerita dan tokoh tersebut sangat populer di Negeri asalnya yaitu India.

Jika pada waktu itu wayang dijadikan media menyampaikan pendidikan Islam oleh para Wali Songo (penyebar agama Islam di tanah Jawa), pada abad modern wayang juga sering digunakan untuk menyampaikan pesan-pesan moral kepada masyarakat, terkadang ada juga pesan yang yang bersinggungan dengan politik, seperti mengkritisi kebijakan pemerintah, baik yang positif atau negatif, ini tergantung pada dalang avilaisinya kemana.

Budaya serta identitas bangsa harus diperjelas dan dipertegas. Sayangnya wayang kulit sudah mulai kurang diminati oleh kalangan muda milenial. Banyak kendala yang dihadapi masyarakat modern ketika mau menikmati pagelaran wayang. Mulai dari waktunya yang terlalu malam sampai kepada bahasa yang masih menggunakan bahasa Jawa kromo.

\section{Wayang kulit sebagai media untuk mengedukasi pendidikan Islam}

Sejarah penyebaran Islam di Indonesia tidak bisa dilepaskan oleh keberadaan para wali. Penyebaran Islam sering dilakukan dengan seni, salah satu keseniaan yang digunakan adalah wayang.

Kesenian wayang yang dipilih para wali untuk menyampaikan nilai-nilai Islam sekaligus meningkatkan persaudaraan. Suluk dan tembang diambil dari ayat-ayat Al Qur'an, sedangkan ceritanya diambil dari tokoh Mahabarata dan Ramayana yang berasal dari India yang mayoritas beragama Hindu. Sunan Kalijaga salah satu wali yang memiliki penilaian bahwa dakwah harus disesuaikan dengan kondisi, budaya masyarakat yang sudah ada jangan lantas ditinggal, akan tetapi dipertahankan sebagai sebuah kenyataan, hanya saja hal- 
hal yang tidak sesuai dengan Islam diubah secara perlahan dengan tujuan mengenalkan Pendidikan Islam.

Adapun cara mengubahnya dengan memodifikasi dan memberi warna baru dari yang masih mengarah ke HinduBudha perlahan sambil dimasukan dengan nilai-nilai ke Islaman. Dengan begitu tanpa disadari sedikit demi sedikit budaya yang lama akan hilang.

\section{Tokoh Punakawan}

Punakawan merupakan bagian dari dunia wayang yang hanya ada di Indonesia, karena di dalam cerita asli pewayangan di India tidak ada tokoh Punakawan. Sedangkan kesenian wayang sendiri sudah ada sejak sebelum kebudayaan Hindu masuk ke Indonesia dan melekat begitu kuat dalam kebudayaan Jawa [2].

Cerita Punakawan juga begitu melekat pada karya komik Tatang.S dimana ada empat tokoh yaitu Semar, Gareng, Petruk dan Bagong. Dari karakter yang dimiliki Punakawan tersebut, maka Punakawan merupakan media yang efektif untuk menyampaikan pesan dan dengan sifatnya yang komunikatif dan fleksibel serta diharapkan mampu untuk berkomunikasi dengan audience. Sebagai media penyampai pesan Punakawan bisa hadir di berbagai media, pada saat di Indonesia masih memiliki satu stasiun televisi (TVRI) maka tokoh Punakawan yang diperankan oleh alm. Ateng dan kawankawan hadir lewat acara 'Ria Jenaka' yang sempat bertahan selama 15 tahun. Mereka bisa menyampaikan kritik sosial, penyuluhan, himbauan bahkan membahas masalah-masalah sosial yang lagi hangat pada saat itu [3].

Keberadaan tokoh Punakawan inilah kemudian Sunan Kalijaga mulai memasukkan unsur-unsur keislaman yang tanpa disadari oleh masyarakat. Islam secara perlahan mulai dikenalkan tanpa membuang tokoh sentral dari Mahabarata.

\section{METODE}

Dalam penulisan ini menggunakan kajian pustaka, yaitu berisi kajian teori yang berhubungan dengan judul penulisan. Kajian pustaka atau studi pustaka merupakan kegiatan yang diwajibkan dalam penelitian, khususnya penelitian akademik yang tujuan utamanya adalah mengembangkan aspek teoritis maupun aspek manfaat praktis.

Dengan menggunakan metode ini penulis dengan mudah menemukan relevansi yang akan diteliti [4].

1. Metode pengumpulan data

Metode pengumpulan data penelitian ini diambil dari sumber data. Yang dimaksud sumber data dalam penelitian adalah subjek darimana data dapat diperoleh. Apabila peneliti menggunakan dokumentasi, maka dokumen atau catatanlah yang menjadi sumber data, sedangkan isi catatan subjek penelitian atau variabel penelitian [5].

2. Teknik analisis data

Setelah data secara keseluruhan terkumpul dilanjutkan dengan menganalisa data tersebut, sehingga dapat ditarik sebuah kesimpulan [6].

\section{HASIL DAN PEMBAHASAN}

Punakawan merupakan tokoh asli asal Indonesia sengaja dimunculkan pada pagelaran wayang kulit oleh Sunan Kalijaga. Semar sebagai tokoh yang dituakan dalam Punakawan yang berperan sebagai penasehat para pandawa selalu menyampaikan pesan-pesan damai di tengah pergolakan politik antara Pandawa dan Kurawa.

Pesan-pesan damai inilah yang kemudian diadopsi dari nilai-nilai yang terdapat pada agama Islam. Hasil observasi dan 
wawancara kepada beberapa orang yang menyukai pagelaran wayang kulit, tokoh Punakawan lebih lekat sebagai sosok yang menebar kebajikan. Kemunculannya selalu dapat menyelesaikan konflik yang terjadi di setiap cerita pagelaran wayang kulit.

Universitas Indraprasta menjadi salah satu kampus yang aktif menampilkan pagelaran wayang kulit serta tidak jarang menyampaikan kontribusi Punawakan membantu pandawa dalam babad alas (membuka hutan untuk dijadikan pedukuhan atau perkampungan).

Pada tokoh wayang seakan ingin menampilkan simbol dari kehidupan yang sebenarnya. Punakawan muncul pada saat goro-goro (sebuah kondisi yang dapat merusak tatanan kehidupan) kemunculan Punakawan membuat para penonton menjadi bersemangat. Kelucuan dan keluguan dari Punakawan serta sikap arif dan bijak yang selalu membawa pesan luhur serta nilai-nilai kehidupan mengubah suasana kacau menjadi kondusif.

Pada intinya Punakawan membawa pesan bahwa Pendidikan Islam harus dijadikan pedoman dalam meyelesaikan permasalahan kehidupan, sebagaimana kontribusi dalam menyampaikan pesan Pendidikan Islam di tengah konflik antara Pandawa dan Kuwara.

\section{Sejarah punakawan}

Dalam dunia pewayangan masyarakat lebih mengenal sosok seperti Yudhistra, Bima, Arjuna, Nakula dan Sadewa. Wajar saja karena kelimanya tergabung dalam kelompok pandawa lima dimana dalam pewayangan mereka merupakan pemeran utama yang berada di pihak yang benar, akan tetapi Sunan Kalijaga dalam dakwahnya memunculkan tokoh yang disebut punakawan, dimana tokoh tersebut tidak pernah ada dalam cerita aslinya. Peran Punakawan dalam menanamkan karakter pada masyarakat di dalam pertunjukan wayang kulit yaitu seperti halnya menjadi penasehat para kesatria, penghibur, kritisi sosial, bahkan sumber kebenaran dan kebijakan. Hal ini selaras dengan pernyataan Kresna, bahwa Punakawan secara karakteristik sebenarnya mewakili profil umum manusia, mereka adalah tokoh multiperan yang dapat menjadi penasehat para penguasa atau satria, bahkan dewa. Punakwan berperan sebagai penghibur, kritikus, sekaligus penyampai kebenaran, kebajikan, dan penganjur keutamaan [7].

Secara epistimologis Punakawan memiliki makna asal dari kata "puna"yang bermakna terang, dan "kawan" adalah teman. Oleh karena itu, Punakawan bisa dikatakan teman hidup yang selalu mendampingi pada jalan yang terang, akan tetapi ada beragam tafsir tentang punakawan itu sendiri.

Dalam menyampaikan misi dan tujuan, misalnya dakwah atau nasihat berupa petuah-petuah filsafat, serta nilai-nilai moral seorang Dalang memerankannya lewat salah satu tokoh wayang kulit yaitu para tokoh Punakawan, dimana Punakawan merupakan tokoh-tokoh dalam pewayangan yang bentuknya aneh dan lucu, termasuk juga watak dan tingkah polahnya. Punakawan, terdiri dari empat tokoh yaitu:

\section{Semar}

Tokoh Semar merupakan pusat dari keseluruhan Punakawan sendiri. Semar banyak disegani oleh para kesatria atau lawan, dimana semar adalah tokoh yang memiliki sifat atau karakter yang rendah hati, tidak sombong, jujur, serta menjadi contoh karakter yang baik dan bijaksana.

2. Gareng

Gareng adalah anak angkat Semar dimana Gareng mempunyai karakter yang berbeda, seorang yang tidak 
pandai bicara apa yang dikatakannya kadang-kadang serba salah. Gareng merupakan tokoh Punakawan yang memiliki ketidak lengkapan bagian tubuh seperti halnya Gareng yang mengalami kecacatan kaki, cacat tangan, dan mata.

3. Petruk

Petruk merupakan anak kedua dari Semar, dimana Petruk memiliki karakter yang nakal dan cerdas. Tokoh Petruk dengan bentuk tubuh, tangan dan kakinya panjang yang menyimbulkan bahwa di setiap pemikiran harus panjang. Seperti halnya kita berpikir harus panjang serta tidak grusa-grusu agar sesuai dengan keinginan dan tidak mengalami penyelesaian. Petruk pandai berbicara dan juga sangat lucu, ia suka menyindir segala hal yang tidak benar dengan lawakan-lawakannya.

4. Bagong

Bagong merupakan anak bungsu semar, dimana tokoh bagong diciptakan dari bayangan semar, bagong memiliki karakter yang sama halnya dengan saudaranya yaitu gareng dan petruk, dimana bagong juga suka bercanda dan penuh dengan kebebasan (berlagak bodoh). [8]

Para tokoh ini sering dijadikan sebagai simbol seorang Figur ideal yang memiliki sifat rendah hati, suka menolong sesama, tidak serakah, melakukan tanpa, mengurangi makan dan tidur, serta menjalankan laku lainnya. Sifat-sifat manusia dalam mitologi Jawa sering kali disimbolkan dengan sifat dan watak dari tokoh-tokoh.

\section{Kontribusi Punakawan dalam Pendidikan Islam dan dakwah}

Raden Said atau yang lebih dikenal dengan Sunan Kalijaga yang memperkenalkan tokoh Punakawan dalam pewayangan. Sunan berusaha menyesuaikan dengan lingkungan sekitar dalam berdakwah.
Sebelum kedatangan Islam wayang begitu melekat pada penduduk Jawa. Keempat figur nama-namanya sama sekali tidak terdapat dalam epos Hindu Ramayana dan Mahabarata sebagai sumber cerita pewayangan aslinya. Menurut pendapatnya, nama Semar, Nala Gareng, Petruk, dan Bagong bukan merupakan sebutan bahasa Jawa kuno, tetapi dari bahasa Arab [9].

Nama-nama Punakawan sendiri yaitu Semar, Nala Gareng, Petruk, dan Bagong merupakan satu-kesatuan yang tidak bisa dipisahkan sebagaimana merepresentasikan karakteristik kepribadian Muslim yang ideal. Semar, berasal dari kata ismar yang berarti seorang yang mempunyai kekuatan fisik dan psikis. Ia sebagai representasi seorang mentor yang baik bagi kehidupan, baik bagi raja maupun masyarakat secara umum. Nala Gareng berasal dari kata nála qarín yang berarti seorang yang mempunyai banyak teman. Ia merupakan representasi dari orang yang supel, tidak egois, dan berkepribadian menyenangkan sehingga ia mempunyai banyak teman. Petruk merupakan kependekan dari frase fatruk ma siwá Allah yang berarti seorang yang berorientasi dalam segala tindakannya kepada Tuhan. Ia merepresentasikan orang yang mempunyai konsen sosial yang tinggi dengan dasar kecintaan pada Tuhan. Bagong berasal dari kata baghá yang berarti menolak segala hal yang bersifat buruk atau jahat, baik yang berada di dalam diri sendiri maupun di dalam masyarakat [10].

Dalam menyampaikan nilai pendidikan Islam Sunan Kalijaga banyak menggunakan simbol dan lambang yang penuh makna. Ini dilakukan agar masyarakat Jawa mudah mengerti dan memahami. Dalam pagelaran wayang kulit munculnya cerita seperti semar mbangun khayangan, pertuk dadi ratu, jurus kalimasada dll. Melalui cerita-cerita 
tersebut, materi-materi dakwah mengenai Islam dimasukkan. Sebagai contoh, dalam cerita Semar Membangun Khayangan dikisahkan bahwa Semar sebagai salah seorang Punakawan, ingin membantu Amarta yang sedang mengalami situasi kritis. Para punggawa Kerajaan Amarta saat itu, mengalami banyak kemunduran karena degradasi moral para pemimpinnya, antara penguasa dan rakyat. Maka dari itu, Semar sebagai Punakawan yang bertugas sebagai penasehat bagi ksatria di Amarta merasa cemas. Kemudian Semar ingin meminjam ketiga pusaka dari Karajaan Amarta yaitu, Jamus Kalimasada, Payung Tunggul Naga, dan Tombak Yudhistira beserta kelima. Pandawa untuk bisa ikut juga datang ke kediaman Semar di Karangkabuyutan. Singkat cerita, Petruk diutus oleh Semar untuk menyampaikan makud Semar tersebut. Akan tetapi, Krishna menolak dengan alasan bahwa itu tidak mungkin dilakukan. Menurutnya, Semar hanya memanfaatkan Pandawa saja [11].

\section{SIMPULAN}

Kontribusi Punakawan dalam menyampaikan Pendidikan Islam kepada masyarakat sebagai tokoh sentral dalam mengedukasi dapat diterima dengan terbuka. Pendidikan Islam menghadirkan nilai-nilai yang baik pada ajaran agama. Apa yang disampaikan sedikitpun tidak mengubah tatanan budaya yang sudah melekat, tanpa adanya kontribusi Punakawan pagelaran wayang hanya sebatas hiburan. Peran dan kontribusi yang sangat menonjol pada tokoh Punakawan dalam pementasan wayang pada masa Sunan Kalijaga banyak membuat orang tertarik dan pada akhirnya membuat masyarakat tertarik dan mengubah kenyakinan yang lama dan memilih untuk masuk Islam. Inilah kearifan dalam mengenalkan nilai-nilai pendidikan Islam sebagai agama baru, sehingga bisa diterima di negeri yang sudah memiliki peradaban dan budaya, tanpa harus menghapus atau menghilangkan budaya yang sudah ada, Islam mampu diterima dengan sangat terbuka oleh masyarakat di bumi nusantara.

\section{DAFTAR PUSTAKA}

[1] E. Setiawan, "Nilai Filosofi Wayang Kulit sebagai Media Dakwah," J. AlHikmah, vol. 18, no. 1, pp. 33-49, 2020 , doi: 10.35719/alhikmah.v18i1.21.

[2] A. J. Darmawan, "Visual Design Face Painting: Language Expressions Stylized for Wayang Punakawan," Humaniora, 2017, doi: 10.21512/humaniora.v8i1.3696.

[3] N. Ranuhandoko dan S. Sidhartani, "Makna Budi Pekerti Melalui Cerita Punakawan: Analisis Visual dalam Seni Kreativitas Komik Kontemporer," Mudra J. Seni Budaya, vol. 34, no. 1, pp. 53-60, 2019 , doi: 10.31091/mudra.v34i1.564.

[4] Sukardi. Metodologi Penelitian Pendidikan: Kompetensi dan Praktiknya / Sukardi. Jakarta: Bumi Aksara, 2009.

[5] S. Arikunto. Prosedur Penelitian suatu Pendekatan Praktik. Jakarta: Rineka Cipta, 2014.

[6] Sugiyono. Memahami Penelitian Kualitatif. Bandung: Alfabeta, 2016.

[7] N. Siswanto, "Filosofi Kepemimpinan Semar," Panggung, vol. 29, no. 3, pp. 254-268, 2019, doi: 10.26742/panggung.v29i3.1011.

[8] W. N. E. Saputra, "Identifikasi Karakteristik Konselor Efektif Berdasarkan Tokoh Punakawan Bagong," J. Konseling dan Pendidik., vol. 4, no. 1, pp. 59-66, 2016.

[9] D. K. Aziz, "Akulturasi Islam dan Budaya Jawa," Fikrah, vol. 1, no. 2, 253-286, 2013.

[10] Marsaid, "Islam dan Kebudayaan: 
Wayang sebagai Media Pendidikan Islam di Nusantara," Kontemplasi $J$. Ilmu-Ilmu Ushuluddin, 2016.

[11] W. J. Sastrawan, "Traces of the Ramayana and Mahabharata in
Javanese and Malay Literature, by Ding Choo Ming and Willem van der Molen (eds.)," Bijdr. tot Taal-, Landen Volkenkd., 2019, doi: 10.1163/22134379-17501009. 